\title{
A Case Report of Neonatal Meningitis and Myocarditis Caused by Enterovirus
}

\author{
Jie Li ${ }^{1}$, Jimei Wang ${ }^{2}$, Min Yang ${ }^{2}$ and Feng Jiang ${ }^{2 *}$ \\ ${ }^{1}$ Department of Neonatology, Jiaxing Maternity and Child Health Care Hospital, China \\ ${ }^{2}$ Department of Neonatology, Obstetrics and Gynecology Hospital of Fudan University, China
}

Submission: November 28, 2019; Published: December 12, 2019

*Corresponding author: Feng Jiang, Department of Neonatology, Obstetrics and Gynecology Hospital of Fudan University, Shanghai, China

\section{Abstract}

Enteroviral infection is very common in newborns. Most newborns recover without serious complications [1]. Invasive neonatal enterovirus infection is rare but often fatal and should be considered in the differential diagnosis with sepsis [2]. We report a case of a neonate who got meningitis and myocarditis caused by enterovirus. A 2-day-old neonate presented with fever. He was diagnosed with enteroviral meningitis. The neonate was hospitalized treated with intravenous immunoglobulin (IVIG) and antibiotics. However, he was diagnosed myocarditis subsequently. Despite those treatment, the newborn ultimately died. We reported a case of myocarditis developing after the diagnosis of enteroviral meningitis. Physicians need to pay attention to clinical conditions of newborns during the treatment of enteroviral infections in newborns.

Keywords: Enterovirus; Meningitis; Neonate; Myocarditis

\section{Introduction}

Enteroviruses consist of polioviruses, coxsackieviruses, echoviruses, and new varieties of enteroviruses that have a clearly different genome. Infection with enterovirus in newborns may result in mild to severe and even critical illness [2]. Unspecific febrile illness is the most common presentation of enteroviral infection. More severe infections may cause sepsis-like syndromes, myocarditis, meningitis, encephalitis, hepatitis, and even death. The mortality in the cases of myocarditis was $44 \%$ $[3,4]$. Newborns are susceptible to get enteroviruses infection via vertical transmission either trans placentally or at the time of delivery. The following case study describes a 38 weeks and 6 days gestational age neonate with meningitis and myocarditis caused by enterovirus.

\section{Case Report}

A male neonate was born through meconium contaminated amniotic fluid by cesarean section to a 30 -year-old, gravida 2 , para 2 mother at 38 weeks and 6 days gestational age and his birth weight was $3480 \mathrm{~g}$. The prenatal labs of the mother were all negative, her pregnancy was uncomplicated. The mother had febrile illnesses about 4 days before delivery. After giving birth, the mother had recurrence of fever and was treated with Ceftriaxone; Newborn APGARs were 10 and 10 at 1 and 5 minutes, respectively.
After birth, he was kept in the room for mothers and infants for 1 day. On the 2nd day, the neonate was noted to be drowsy and with a body temperature of $37.8^{\circ} \mathrm{C}$. No action has been taken other than encouraging breastfeeding. On the 3rd day, the neonate was grunting, with reduced tone. He was transferred to the NICU and received oxygen. The laboratory tests showed that the leukocyte (WBC) count was $8500 / \mathrm{ml}$ (lymphocytes, 25.5\%; neutrophils, $65.0 \%$ ) and the level of C-reactive protein (CRP) was $12.0 \mathrm{mg} / \mathrm{L}$. A chest X-ray showed no infiltrates. The TORCH tests were negative. We started with meropenem and vancomycin considering early-onset neonatal sepsis. The fever persisted, and lumbar puncture was performed on the $4^{\text {th }}$ day of hospital. Examination of cerebrospinal fluid showed that the number of WBC was 1840/ $\mathrm{ml}$ (lymphocytes, 10\%; neutrophils, 60\%; monocytes $30 \%$ ), the glucose level was $2.0 \mathrm{mmol} / \mathrm{L}$ and the study of protein level was $227.1 \mathrm{mg} / \mathrm{dl}$. The PCR of enterovirus was positive but the latex agglutination tests for bacteria were all negative. The neonate was diagnosed with enteroviral meningitis and treated three times with IVIG (100 mg/kg/day). On hospital day 7, the breathing rate was 80 breaths/min and the heart of the newborn was 200 beats/min. EEG showed paroxysmal supraventricular tachycardia and frequent ventricular premature beats. A repeated CSF study showed that the leukocyte count was $180 / \mathrm{ml}$ (lymphocytes, 
50\%; neutrophils, $20 \%$; monocytes $30 \%$ ), the glucose level was $2.34 \mathrm{mmol} / \mathrm{L}$ and protein level was $181.7 \mathrm{mg} / \mathrm{dl}$. Laboratory tests showed a leucocyte count of 11200/ml (lymphocytes, 37.1\%; neutrophils, $37.2 \%$ ) , C-reactive protein (CRP) of $18.1 \mathrm{mg} / \mathrm{L}$, alanine transaminase level of $56 \mathrm{U} / \mathrm{l}$, aspartate transaminase level of $128 \mathrm{U} / \mathrm{l}$, lactate dehydrogenase level of 1102U/l, B-type natriuretic peptide(BNP) level of $>25000 \mathrm{pg} / \mathrm{ml}$ and creatine phosphokinase level of $400 \mathrm{U} / \mathrm{l}$. Troponin-I and Creatinine kinase muscle brain (CK-MB) increased to $6.97 \mathrm{ug} / \mathrm{l}$ and $275 \mathrm{u} / \mathrm{L}$, respectively. His blood gas was normal, but his chest $\mathrm{x}$-ray revealed pneumonia. Echocardiography showed mitral regurgitation, decreased wall motion, small amounts of pericardial effusion with left ventricular ejection fraction of $33.2 \%$ and atrial septal defect. Acute respiratory failure and myocarditis was diagnosed. Ventilator care, diuretics, cardiotonic was administered; despite the treatment, symptoms were exacerbated and ultimately fatal. Written informed consent was obtained from the parents of the newborn. This study was approved by the Ethics Committee of Jiaxin Maternity and Child Health Care Hospital.

\section{Discussion}

More than 100 serotypes have been identified to date [5]. New types of enteroviruses have a distinctly different genome. Enteroviruses are small RNA viruses belonging to the Picornaviridae family. EVs are known to be the leading cause of febrile and aseptic meningitis in neonates, as well as potentially lethal neonatal infections such as meningoencephalitis, hepatitis, and myocarditis. Intrauterine infection is rare, but it can be rapidly fatal [6,7]. $60-70 \%$ of newborns diagnosed with enterovirus infection are infected at the time of delivery in the first 10 days of life. The risk factors for critical neonatal disease include the absence of neutralizing antibody, prematurity, maternal illness during the perinatal period, early age, and more virulent viruses infection [8]. The diagnosis of EV infection has been based on positive viral culture, nasopharyngeal swab, stool or cerebrospinal fluid. However, new nucleic acid amplification methods such as PCR for viral RNA identification are more sensitive and have replaced viral culture as standard $[9,10]$. In our case, enterovirus was detected by RT-PCR in cerebrospinal fluid. Meningitis and myocarditis in neonates can cause significant long-term morbidity [9]. Immunoglobulin has been used in neonates as a therapeutic agent, but clinical efficacy has not been demonstrated. Specific antiviral treatment is not available. Therefore, the treatment is favorable and adapted to dysfunction of organs, including cardiotonic and ventilation. This case study describes a rare case of meningitis and myocarditis after a diagnosis of enteroviral infection. It is important for physicians to remember that enteroviral infections have a poorer prognosis in neonates than in older children.

\section{Conclusion}

Neonatal meningitis and myocarditis caused by enterovirus are rare but often fatal and should be considered in the differential diagnosis in febrile neonates. For clinicians caring for neonates, it is important to consider a general differential diagnosis in neonates with sepsis-like illness. virologic diagnosis can be done quickly by polymerase chain reaction (PCR). Early treatment and prevention measures are the only guarantors of a reduced in morbidity and mortality.

\section{Acknowledgment}

The authors thank Zhang Fan, who have been a source of encouragement and inspiration.

\section{Funding}

This research did not receive any specific grant from funding agencies in the commercial, public, or not-for-profit sectors.

\section{Conflict of Interest}

The authors declare that there is no conflict of interests regarding the publication of this paper.

\section{References}

1. Wilfert, CM, SN Lehrman, S.L. Katz (1983) Enteroviruses and meningitis. Pediatr Infect Dis 2(4): 333-341.

2. Tebruegge M, N Curtis (2009) Enterovirus infections in neonates. Semin Fetal Neonatal Med 14(4): 222-227.

3. Freund MW, Kleinveld G, Krediet TG, van Loon AM, Verboon-Maciolek MA (2010) Prognosis for neonates with enterovirus myocarditis. Arch Dis Child Fetal Neonatal 95(3): 206-212.

4. Jordán I, Esteva C, Esteban E, Noguera A, García JJ, et al. (2009) Severe enterovirus disease in febrile neonates. Enferm Infecc Microbiol Clin 27(7): 399-402.

5. Khetsuriani N, Lamonte-Fowlkes A, Oberst S, Pallansch MA, Centers for Disease Control and Prevention (2006) Enterovirus surveillance-United States, 1970-2005. MMWR Surveill Summ 55(8): 1-20.

6. Strong BS, SA Young (1995) Intrauterine coxsackie virus, group B type 1, infection: viral cultivation from amniotic fluid in the third trimester. Am J Perinatol 12(2): 78-79.

7. Willems A, Benne CA, Timmer A, Bergman KA (2006) Fatal illness associated with pulmonary hypertension in a neonate caused by intrauterine echovirus 11 infection. Am J Perinatol 23(1): 59-61.

8. Abzug MJ (2004) Presentation, diagnosis, and management of enterovirus infections in neonates. Paediatr Drugs 6(1): 1-10.

9. Schlesinger Y, MH Sawyer, GA Storch (1994) Enteroviral meningitis in infancy: potential role for polymerase chain reaction in patient management. Pediatrics 94(2): 157-162.

10. Reinheimer C, Rabenau H, Berger A, Doerr HW (2011) Diagnostic of neurotropic enteroviruses in children with CSF and/or stool: virus isolation by cell culture or PCR? Klin Padiatr 223(4): 221-226. 
This work is licensed under Creative Commons Attribution 4.0 Licens

DOI:_10.19080/AJPN.2019.08.555797

\section{Your next submission with Juniper Publishers} will reach you the below assets

- Quality Editorial service

- Swift Peer Review

- Reprints availability

- E-prints Service

- Manuscript Podcast for convenient understanding

- Global attainment for your research

- Manuscript accessibility in different formats

( Pdf, E-pub, Full Text, Audio)

- Unceasing customer service

Track the below URL for one-step submission

https://juniperpublishers.com/online-submission.php 